\title{
The Incorporation of Emotion Regulation Struggles in Highly Complex Developmental Traumatized Individuals
}

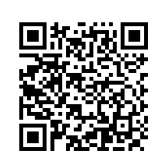

\author{
Eda Yllmazer* \\ Department of Psychology Doctorate, Uskudar University, Turkey
}

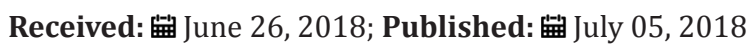

*Corresponding author: Eda Yılmazer, Department of Psychology Doctorate (phd) Programme, Uskudar University , Turkey

\begin{abstract}
This systematic review aim is to investigate the effects of child maltreatment and developmental complex trauma on emotion regulation. For this aim; articles published in PubMed, Web Of Science and Elsevier databases between 2009-2016 were scanned. In this review, 11 empirical articles in English were analyzed based on inclusion/exclusion criteria. These studies highlight that, children and adolescents who are exposed to maltreatment during childhood exhibit deficits in regulating their emotions. As studies show, the reason behind Complex Developmental Trauma is a repetitive and ongoing form of neglectful or abusive parenting. If parents lack of ability to provide enough and necessary attention to their child, he/she will not be able to control themselves or their actions. In brief, if children do not find a "secure place" for themselves during infancy, they will be more prone to experience some difficulties in regulating their moods and emotional responses when they become adults. Infants with traumatic history tend to be aggressive, isolated and disengaged and unfortunately, they may develop many psychiatric illnesses such as; depression, anxiety disorders, eating disorders, dissociation etc...in the future. Secure attachment pattern helps us create our inner maps that affect our relationships throughout life.
\end{abstract}

\section{Emotion Regulation}

Children who experience complex developmental trauma have difficulties in identifying and expressing their emotions compared to non-maltreated children. Maltreated children are more likely to suffer from significant depression, anxiety, frustration or anger in their adulthood. They usually respond to various situations in an unpredictable and fierce way. Even unthreatening situations make maltreated children tremble, angry, sad and isolated. These children so often experience flashbacks of traumatic events from their environment. If flashbacks of trauma occur repeatedly, stress hormones impress those memories profoundly in the mind making it harder for them to enjoy and feel satisfied by an ordinary life because they are imprisoned in the past. Children who have intense and negative feelings will have difficulty calming themselves down. Childhood trauma experiences are so disruptive that they are internalized by the child and they change their physiology. Complex Developmental Trauma suppresses the prefrontal cortex, which has a vital importance regarding impulse control, decision making and regulating social behaviors. The executive capacities of the prefrontal cortex enable people to observe what is going on around them, predict what will happen if they take a certain action, help them make conscious choices, act calmly and control their obsessive thoughts, feelings and emotions. This capacity is crucial for human beings to continue their relationships with each other. As long as the frontal lobes are functioning properly, individuals are unlikely to lose their temper in inappropriate situations. FMRI studies show that there are measurable differences in brain activations of the amygdalas and prefrontal cortexes of non-maltreated and maltreated children [1]. Traumatized people generally escape from their emotions. Although their neglectful or abusing caregivers are no longer existing in their present, they still react in a way as if those people are influencing their lives. Even their physical responses are due to their traumatic history and they react to things around them as threats.

Even though the trauma is not a current issue, the emotional brain continues producing sensations that makes the trauma survivor feel scared and lost all the time. It is predicted that so many trauma survivors turn into binge eaters, alcoholics or drug addicts. They tend to avoid building romantic relations and prefer not to socialize. They unfortunately carry the risk of developing personality disorders in the future [2]. As Leahy, Tirch \& Napolitano et al. [3] stated, an individual is uncapable of regulating emotions, this means that a person cannot process emotions and filter experiences as dangerous or safe. Emotion regulation is a very important element of individual development and is also an effective part of interpersonal relationships. Emotion regulation is an important skill in managing an individual's problems in stressful 
and difficult situations. (Dempsey, 1996; akt. Onat ve Otrar, 2010). Emotion regulation consists of internal and external processes that are responsible for changing the emotional response to achieve goals and to control and evaluate situations rationally. Intense negative emotions may cause terror, trauma, fear, impatience, uneasiness, anxiousness or a sense of urgency.

On the other hand, apathy may cause dissociation such as: amnesia, identity alteration, depersonalization, identity confusion, fugue or derealization. It is very challenging for many traumatized children to describe their feelings because they are un capable of identifying even their physical sensations. Not being able to explain what is happening in their bodies and minds, makes them out of touch with their needs. Parents or first caregivers should guide their children to satisfy and establish control over their needs [4]. Emotion regulation is an essential part of auto regulation and self-esteem. On the other hand, neglectful, abusive caregivers block the development of healthy emotion regulation skills of their children. Children who experience complex developmental trauma during their infancy develop "ADHD" and are known to become "problematic" and "maladaptive" in their adolescence and adulthood. If a child is exposed to sexual, physical or emotional abuse during childhood, it is very probable that they will develop mental illnesses, sexual problems or unhappy romantic or social relationships in the future. In the light of previous studies, it is clear that there is a positive correlation between child abuse and psychological illnesses such as; attention deficits, hyperactivity disorder, depression, anxiety disorders, posttraumatic stress symptoms, eating disorders, alexithymia, dissociation, substance abuse, oppositional defiant disorder, personality disorders and lack of self-respect [5].

\section{Effects of Complex Trauma on Emotion Regulation}

Children who are abused and neglected are often more alert than other children. It is obvious due to their increased heart rate, blood pressure rates and high levels of stress hormones (adrenaline, cortisol, norepinephrine) present in their immune system and their sympathetic nervous system. As a result, these children have compromised immune systems and they are more susceptible to illness. It is not possible to gain emotional equilibrium in adulthood if children are exposed to repetitive chronic stressors in an insecure environment with ongoing pain and suffer. Unfortunately, they are confined to live with chronic anxiety and terror throughout their lives. Securely attached children are aware of others emotions and thoughts. They establish empathy towards others and acquire a sense of security. Bowlby's and Winnicott's theory focuses mainly on securely attached children and this theory is influential in child development. Overwhelming complex developmental trauma destroys the self-regulatory system and as a result, trauma survivors never find a chance of maintaining emotional security throughout their lives.

Securely attached children usually become good-natured and coherent playmates. They build good relationships with their peers. They can easily notice changes in voices and faces of others and adjust their behaviors according to needs arising in different situations. Abused kids are often responsive to physical stimuli such as, changes in tone of voice and facial expressions. They often react to them as threats. When those relationships with others are unstable or unpredictable, children learn that they cannot rely on and trust other people. When primary caregivers abuse and mistreat their child, they identify themselves unfavourable, invaluable and inadequate and as a result they develop a negative perception about the World in their minds [6]. Children with unhealthy attachments have difficulty in coping with stress. Concerned first caregivers or parents have a positive impact on their children's healthy development, mainly the brain, body and emotional systems. Children who are survivors of developmental complex trauma are more likely to develop unhealthy relations with their romantic partners, friends and authority figures (teachers, police officers...) in the future.

They cannot establish a healthy connection between their childhood memories and their current lives. They feel alive and alert only when they revisit their traumatic past or if something makes them remember their past traumas. Trauma leaves an imprint in the mind, body and brain. This imprint causes so many consequences about how people manage to live and survive in the present and in the future [7]. Blaustein and Kinniburgh [5] suggested that "if children exposed to chronic stress with abuse and if it has a repeated and ongoing pattern by their first caregivers or parents, it is called "complex developmental trauma". These children are generally exposed to disorderly and uncertain environments, and they do not have any caregivers to protect and contain them because unfortunately, these caregivers are the main reason behind those traumas. If children do not have the opportunity to learn how to soothe themselves when they feel stressed, worried, frustrated or angry, these children will develop impulsive reactions and become easily agitated. For example, at school they may become so frustrated that they give up on even small tasks that present a challenge.

They cannot focus their attention for a specific amount of time so their teachers assume they have attention deficits. Children who have experienced repeated intense and prolonged traumatic events are more sensitive to every stimulus in their environment. If you don't feel secure on the inside, it is difficult to identify the difference between security and danger. If the child thinks that they are terrible individuals and they will expect other people to treat them in the same violent way. The child will think that they deserve such treatment and accept that there is nothing else to do to change the world. In the early years of childhood, if children are surrounded by violence and abuse at home from their most loved ones, they learn that they cannot trust anybody and that the world is a dangerous and unsafe place. They see themselves as weak individuals that are un capable of doing anything to change this situation [7]. If a child experiences a complex developmental trauma, they won't be able to build a satisfactory and functional relationships. Due to the lack of expected qualities during elementary or middle school years, traumatic children experience low school success and unhealthy peer relationships.

Eventually, they feel un assured and unqualified. This core belief leads to negative self-concept, low self-esteem and lack 
of self-respect. If children don't have proper emotion regulation strategies, they will experience difficulty in adapting themselves to stressed environments. Since a traumatic child behaves as if others are his/her enemies and are source of threats, he/she becomes isolated and never finds a way to heal their pain and never take the chance of getting away from this vicious cycle. They will never feel free from their pains and repeated [8]. Human beings cannot live isolated lives because one of the basic needs of human beings is building up relationships and staying in touch with others in safe environments, especially their first caregivers. This is also related to the fact that everyone is struggling for taking part in society. It is expected from adults to self-regulate emotionally and physically and to care for the needs of their bodies and souls at the same time. If children are lucky to grow up in a family without abuse, neglect, ignorance and insultation, they will become a healthy individual in the future. Growing up in a family with reliable sources of comfort, strength, trust and care is an advantage for children throughout their life.

As a result, they will develop self-awareness, empathy, impulse control and self-motivation that helps them to be a part of the larger social culture [7]. Adolescents make attempts to separate themselves from their parents and find their identities that will last until the end of their lives, but there is a big dilemma that the adolescents face at this period of development. They are not completely ready or brave enough to split away from their parents and they will still seek a secure place for themselves. They look for ways to fly on their own wings without asking for help from their caregivers, but at the same time they want to be assured that there is a safe nest for them to turn back to in the end of their journey. If there is an ongoing pain and chronic stress and trauma in their environment, this will turn into a disaster and their future may be under threat. Unfortunately, they will end up becoming drug users and have isolated characters with dissociative symptoms, emotion dysregulation etc.

All these symptoms will act as a tool to escape from pain and trauma. As a result of these reactions, adolescents stay away from their peers and cannot build up healthy relations with the rest of the society. They cannot succeed in individualization and separation. Traumatic adolescents do not establish feelings of belongingness to their families and to the society, so they make unhealthy and risky friendships which may contain insult or abuse. And consequently, these children cannot get rid of this vicious cycle that is following them since their childhood [5]. The main purpose of this study is to answer the question "Does developmental complex trauma affect emotion regulation and how?". To inquire this matter, the present article carried a systematic review of studies investigating the effects of childhood trauma on emotion regulation and its association with some other mediators and discusses methodologies used.

\section{Method}

A systematic review was carried through studies particularly looking into the outcomes of exposure to childhood developmental trauma on emotion regulation. Pubmed, Elsevier and Web Of Science databases were scanned for the terms: "trauma", "complex trauma", "maltreatment", "emotion regulation" and "emotion dysregulation". The articles acquired were filtered based on these features: presence of an abstract, empirical study, issued in a peerreviewed journal and presence of a reference list. Although there are so many researches done specifically on the effect of sexual abuse on emotion regulation, they are not included in this review because they only studied the sexual abuse, not complex developmental trauma. Depending on the inclusion criteria, the initial articles were reduced to 39. After examining them in depth, 18 articles were omitted as their aim was not accommodated with the present study. After excluding 18 articles, 11 articles were added to the present systematic review. The researchers which were included are the ones that shared the objectives of the present review and the ones who intended to offer new ideas to future studies.

\section{Results}

Key study findings are described in Table 1 and summarized below. In the study performed by Lisa Hopfinger and her colleagues, they worked to emerge how emotion regulation mediates the effect of childhood trauma on depression. They found that if childhood trauma increased, emotion regulation decreased, thus showing that there is a negative correlation between two variables. Another finding is that the severeness of depression is also a consequence of both childhood trauma and emotion dysregulation. When Emotion regulation scores increase, depression scores decrease. If childhood trauma increases, depression increases afterward. The study by Abigail P. and colleagues' was to clarify whether emotion dysregulation mediated the relationship between PTSD symptoms and dissociation. They examined the scores through multiple linear regression models. Due to PTSD symptoms and emotion dysregulation, dissociative symptoms develop. At the end of the study, it was proved that emotion dysregulation is an important and dominant predictor/outcome of child and adult trauma exposure. As a result, relevant to the literature discussed before, maltreated childhood trauma survivors exhibit emotion dysregulation and deficits in cognitive processing.

Table 1: Studies Describing Childhood Maltreatment (childhood trauma, complex trauma)and Emotional Regulation.

\begin{tabular}{|c|c|c|c|}
\hline Author (year) & Sample & $\begin{array}{c}\text { Measures of emotional } \\
\text { regulation }\end{array}$ & Findings \\
\hline & & CTQ Short form & $\begin{array}{c}\text { Individuals with more severe experience } \\
\text { of maltreatment in childhood and adolescence } \\
\text { reported more maladaptive emotion regulation } \\
\text { Wolff S et al. }\end{array}$ \\
{$[21]$} & Age: $19-65$ & Found a positive relationship between physical \\
& (Childhood Trauma Questionnaire) & neglect, emotional abuse and physical abuse \\
& & and all facets of emotion dysregulation.
\end{tabular}




\begin{tabular}{|c|c|c|c|}
\hline $\begin{array}{c}\text { Thomas C et al. } \\
\text { [19] }\end{array}$ & $\begin{array}{c}\text { n: } 3902 \\
\text { Age: } 18-81 \\
\text { Female: } \% 68.9\end{array}$ & $\begin{array}{l}\text { Childhood Trauma Questionnaire } \\
\text { (CTQ) } \\
\text { Emotion Dysregulation Scale, short } \\
\text { version } \\
\text { (EDS) } \\
\text { Beck Depression Inventory }\end{array}$ & $\begin{array}{l}\text { All variables were correlated, childhood emotional } \\
\text { abuse was correlated with both current } \\
\text { emotion dysregulation and current depression } \\
\text { symptoms. }\end{array}$ \\
\hline Abigail P et al. [15] & $\begin{array}{l}\text { n: } 154 \\
\text { Median age: } 42 \\
\text { Female:\%80 }\end{array}$ & $\begin{array}{l}\text { Childhood Trauma Questionnaire } \\
\text { (CTQ) } \\
\text { Traumatic Events Inventory } \\
\text { (TEI) } \\
\text { Clinician Administered PTSD Scale } \\
\text { Difficulties in Emotion Regulation } \\
\text { Scale } \\
\text { (DERS) } \\
\text { Multiscale Dissociation Inventory } \\
\text { (MDI) }\end{array}$ & $\begin{array}{l}\text { Emotion dysregulation was an important forecaster of } \\
\text { study, individuals with traumatic history, showed emotion } \\
\text { both child and adult trauma exposure. In this } \\
\text { dysregulation. }\end{array}$ \\
\hline $\begin{array}{c}\text { Lisa } \mathrm{H} \text { et al. } \\
\text { [18] }\end{array}$ & $\begin{array}{c}\mathrm{n}: 148 \\
\text { Age:18-70 } \\
\text { Female:\%55 }\end{array}$ & $\begin{array}{l}\text { Emotion Regulation Skills(ERSQ) } \\
\text { Hamilton Rating Scale for } \\
\text { Depression } \\
\text { (HRSD-24) } \\
\text { Childhood Trauma } \\
\text { Questionnaire(CTQ) }\end{array}$ & $\begin{array}{c}\text { Childhood trauma explained } \% 4.9 \text { of the variance in } \\
\text { general emotion regulation. The association was negative; as } \\
\text { childhood trauma increased, emotion regulation declined.(and } \\
\text { vice versa) }\end{array}$ \\
\hline $\begin{array}{l}\text { Lenneke R et al. } \\
\qquad[12]\end{array}$ & $\begin{array}{c}\text { n: } 111 \\
\text { (maltreated boys) } \\
\text { n: } 110 \\
\text { (nonmaltreated } \\
\text { boys) } \\
\text { Age: } 7.5-10.42\end{array}$ & $\begin{array}{l}\text { Maltreatment Classification System } \\
\text { Relatedness Questionnaire } \\
\text { Emotion Regulation Q-Scale }\end{array}$ & $\begin{array}{l}\text { According to the results of the t-tests, maltreated children } \\
\text { scored lower on the emotion regulation scale than } \\
\text { nonmaltreated children. Children who had an } \\
\text { insecure pattern of attachment. Maltreatment was related to } \\
\text { emotion dysregulation }\end{array}$ \\
\hline $\begin{array}{c}\text { Tanja J et al } \\
\text { [13] }\end{array}$ & $\begin{array}{l}\text { n: } 67 \text { female } \\
\text { Mean age: } 40\end{array}$ & $\begin{array}{c}\text { Traumatic Events Inventory(TEI) } \\
\text { Childhood Trauma Questionnaire } \\
\text { Modified Posttraumatic Stress } \\
\text { Disorder Scale } \\
\text { Beck Depression Inventory-II } \\
\text { Emotional Conflict Regulation } \\
\text { Behavioral Task }\end{array}$ & $\begin{array}{c}\text { MANCOVA results showed } \\
\text { difference in emotional regulation scores } \\
\text { found that individuals who reported exposure to } \\
\text { based on reported exposure to childhood abuse. It's } \\
\text { childhood abuse showed poorer emotional conflict regulation }\end{array}$ \\
\hline Christine $\mathrm{H}$ et al. & $\begin{array}{c}\text { n: } 1632 \\
\text { female: } \% 63.3 \\
\text { Age: } 18-90\end{array}$ & $\begin{array}{l}\text { Childhood Trauma Questionnaire } \\
\text { Traumatic Events Inventory } \\
\text { Emotional Dysregulation Scale } \\
\text { Adult Attachment Protype } \\
\text { Questionnaire }\end{array}$ & $\begin{array}{l}\text { Controlling for gender, age and household monthly income } \\
\text { and total level of nonchildhood abuse trauma exposure, used } \\
\text { univariate analysis of variance to state if emotional dysre } \\
\text { gulation levels change according to the level of childhood } \\
\text { abuse }\end{array}$ \\
\hline $\begin{array}{c}\text { Anna S et al. } \\
{[10]}\end{array}$ & $\begin{array}{c}\text { n: } 394 \\
\text { age: } 18-65 \\
\text { Female: } \% 82.4\end{array}$ & $\begin{array}{c}\text { Depression PHQ-9 } \\
\text { Childhood Maltreatment CTQ } \\
\text { Emotion Regulation Scale DERS }\end{array}$ & $\begin{array}{l}\text { CM was related to difficulties in emotion regulation, relation } \\
\text { ships and thinking style and symptoms of posttraumatic stress } \\
\text { disorder. }\end{array}$ \\
\hline
\end{tabular}

Emotional dysregulation and depression severities in adults are associated with past exposure during childhood to emotional abuse, neglect and insult by the parents and primary caregivers. According to the wide study that examined whether complex trauma and emotional dysregulation are relevant to depression tendency, it has been found that all three variables are correlated. Adult depression can be the consequence or a side effect of childhood trauma and emotion dysregulation. Wolff S. and colleagues described that SUD is developed due to emotional and physical maltreatment. It's been found that individuals with more severe experience of maltreatment in childhood and adolescence reported more maladaptive emotion regulation. Maltreatment was not only associated with SUDs but 
also with emotion dysregulation. There is a positive relationship between physical neglect, emotional abuse and physical abuse and are all investigated with the aspects of emotion dysregulation. The results corresponded to the findings of the previous researchers that several types of maltreatment are related to more difficulties in emotion regulation. Robert TM et al. [9] conducted an investigation with a clinical sample of 46 maltreated children.

The study found a significant relation between overall PTSD and internalizing behavior problems. Empathy and emotion dysregulation were significantly associated with overall PTSD. The effects suggested that maltreated children are unable to regulate their emotions and are at a greater risk of experiencing traumarelated symptom matology. This finding is consistent with the research demonstrating that maltreated children who manifest increased arousal often experience a wide range of dysregulated emotions and behaviors such as hyperactivity attention deficits and irritability (Lipschiz, Morgan \& Southwick, 2002). Anna S, et al. [10] proposed mediators of the relationship between CM and depression were applied on a large group of individuals with clinical depression. CM and depression are associated with the proposed mediator's emotion regulation difficulties and maladaptive adult attachment. In the study, it's revealed that about $64 \%$ of the sample experienced at least one traumatic event according to DSM 4 -TR criteria of trauma in their lives. Each mediator clarifies associations with depression and $\mathrm{CM}$ in the analyses. According to the multiple mediation models; the severity of childhood maltreatment is related to difficulties in emotion regulation, isolation, escaping from society and avoidance in close relationships, depression symptoms and PTSD.

Erin B. et al. [11] examined the relationship between emotion regulation with child abuse and subsequent posttraumatic stress. The first hypothesis of the study was that maltreated children experience greater emotion dysregulation compared to nonmaltreated children. Results of independent samples t-tests showed that sexually abused children get high scores on emotion dysregulation compared to non-abused kids. Total DERS score and the PTS total scores are positively correlated. Pearson Correlations reported the Emotion Regulation Difficulty in Subscales of difficulties in terms of "Emotion Regulation Scale (DERS)" and retrospectively reported Child Maltreatment in "The Child Trauma Questionnaire". Lenneke A et al. [12] attempted to identify the mediating effects of mother-child primary relationship styles and emotion regulation. Comparing the means and standard deviations of maltreated and non-maltreated children, it is significant that internalizing kind of emotion regulation pattern exists in maltreated and abused children. The t-test results showed that maltreated children have lower scores on the emotion regulation scale than non-maltreated children. Maltreated children were presented as a risk group for emotion dysregulation. Bekh B, et al. [13] aimed to clarify the effect of childhood maltreatment and oxytocin receptor single nucleotide polymorphism on emotional regulation and attachment styles.

It came to the conclusion that when childhood trauma scales results increases, emotional regulation scales scores decreases. Children who were exposed to maltreatment and abuse in their childhood showed emotion dysregulation in adulthood. Controlling gender, age and monthly income (salary) and the total level of non-childhood abuse trauma exposure, used univariate analysis of variance to determine if emotional dysregulation levels differed with respect to childhood abuse. It was found that there is a doseresponse relationship between childhood maltreatment and emotional dysregulation. Bekh B et al. [13] investigated whether there is an association between childhood abuse, PTSD and emotion dysregulation. Multivariate analysis of covariance showed significant differences in emotion regulation scores between children who were abused and those who were not. Children who are exposed to severe abuse had lower emotion regulation scores.

\section{Discussion}

Analysis of the articles in this systematic review supported the previous knowledge that exposure to childhood maltreatment is associated with emotion dysregulation. Emotional regulation is a critical issue in managing the effects of trauma and neglect. If teachers, parents and mental health professionals were thoroughly trained in emotional regulation techniques, it would have made an enormous positive difference. Five of the studies included in this review have a common population of low-income AfricanAmerican sample with disadvantaged characteristics and who were exposed to trauma. This disadvantaged group remained confronted with terrible consequences such as depression, anxiety disorders, substance use disorders, PTSD... It can be thought that the homogeneity of the sample is the positive and powerful side of this study because rest of the studies chose the White people, women, people who have many facilities or educated people as a sample of their research and this can be seen as a limitation. It is very useful to choose this group because African-American people cannot reach public health centers or treatments of trauma easily.

Instead of healing their pains, they are condemned to live with their traumas and face their devastating consequences. It is necessary to increase the number of studies implementing disadvantaged groups dealing with complex developmental trauma because, in the light of these investigations, new and advanced treatments will be planned for the sake of these trauma victims by the mental health institutions and mental health professionals. It may transform into a worldwide cooperation against childhood trauma and may offer different healing ways or treatment models (EMDR, psycho-education, adapting the ARC model etc..) for disadvantaged groups in countries that seek help. The effective way of healing complex trauma depends on the improvement of emotion regulation. And in order to achieve this improvement, teachers and instructors in the education system should be trained in emotion regulation techniques and special treatment models. Cicchetti et al. [14] reported that children with low economic social status are more likely to develop disorganized, anxious, withdrawn and insecure kinds of attachment styles.

The other six researches focused on finding out if childhood abuse, maltreatment and neglect are associated with emotion regulation difficulties but these six researches are not carried out with the same demographic variables as the other five studies which 
were applied with the incident selected low SES sample. Although the results of these studies are valuable for the previous literature regarding the role of emotional dysregulation in the association between maltreatment and substance use, psychopathology, posttraumatic stress, depression etc, nevertheless the following limitations must be taken into consideration. First, the researches that are taken in the review are cross-sectional study designs and this limits the possibility to draw causal conclusions. All the results supported the theories that emotion regulation is an important outcome of childhood trauma but on the other hand, longitudinal prospective studies are needed to minimize the confounding variables and chance to observe every other vital important event in the lives of the victims. A longitudinal study with traumatized individuals would enable us to examine interpersonal relationships that may have an influence on variables of the study.

Traumatized individuals should be accompanied over long periods of time with repeated observations of the same variables (parents, victims). Longitudinal studies are needed to examine the hope of answering developmental, temporal questions and the developmental relationship of genetic risk, early life stressors, emotion dysregulation and psychopathology. Another limitation of this review is the method of assessment. Self-report instruments/ questionnaires were used for childhood abuse and emotional regulation. Self-report measures and scores of emotion regulation abilities and childhood trauma scores must be looked at with suspicion because these responses may not reflect the truth depending on the individual's way of answering the questions. Individuals may answer honestly or insincerely. They may be biased or influenced by their behavior or experiences during their childhood. Instead of these questionnaires, Chris Perry and Van der Kolk designed an interview instrument called "The Traumatic Antecedents Questionnaire". This is a depth interview with predetermined questions.

The interview starts with some simple questions and progresses gradually to more revealing questions. And in this interview, the patients do not have the option to escape when he/she doesn't feel like answer. On the other hand, research indicates that the experience of emotions is universal; however, the type and degree to which individuals display emotions may vary across cultures. Caregivers' beliefs about emotional expression, often based on cultural norms and are likely to influence children's emotional development. Future research should consider the influence of culture - individualistic vs collectivistic cultures. Studies may have discussed and suggested ways of healing from trauma and placed guide treatment for future studies in the research papers. Traumatized people can be healed only by being together with other human beings. Being synch with others means getting and giving support to each other is the only effective way to overcome the symptoms of trauma. In the simplest way these people can be family members, loved ones, AA meetings, religious communities, psychodrama groups, group therapies or professional therapists. By the help of these people, individuals find physical and emotional safety.

\section{References}

1. Yael D, Julian F, Michael H, Jean F (2014) Childhood Maltreatment, Emotional Dysregulation, and Psychiatric Comorbidities. Harv Rev Psychiatry 22(3): 149-161.

2. Alink LRA, Cicchetti, Kim DJ, Rogosh FA (2009) Mediating and moderating processes in the relation between maltreatment and psychopathology: Mother-child relationship quality and emotion regulation. Journal of abnormal child psychopathology 37(6): 831-843.

3. Leahy RL, Tirch D, Napolitano LA (2011) Emotion regulation in psychotherapy. New York: Guilford Press.

4. Shields A, Cicchetti D (2001) Parental maltreatment and emotion dysregulation as risk factors for bullying and victimization in middle childhood. J Clin Child Adolesc Psychol 30(3): 349-363.

5. Blaustein ME, Kinniburgh KM (2010) Treating traumatic stress in children and adolescents: How to foster resilience through attachment, self-regulation, and competency. New York: Guilford Press.

6. Bowlby J (1988) A secure base: Parent-child attachment and healthy human development. USA: Basic Books.

7. Van Der Kolk BA (2015) The body keeps the score: Brain, mind, and body in the healing of trauma [Kindle DX version]. The Penguin Group, New York, India.

8. Saxe GN, Ellis BH, Kaplow JB (2007) Collaborative treatment of traumatized children and teens. Guildford Press, New York, India.

9. Robert M, Angela V, Sheila K, Susan R (2013) Emotion regulation and psychopathology in a sample of maltreated children. Journal of child and adolescent trauma 6: 25-40.

10. Anna S, Antje K, Jens B, Thomas E (2016) What mediates the link between childhood maltreatment and depression? The role of emotion dysregulation, attachment, and attributional style. Eur J Psychotraumatol $7(10): 32652$.

11. Erin B, Joan J, Hilary H (2010) Child Maltreatment, emotion regulation, and posttraumatic stress: The impact of emotional abuse. Journal of aggression 19(8): 801-819.

12. Lenneke A, Jungmeen K, Fred R, Dante C (2009) Mediating and moderating processes in the relation between maltreatment and psychopathology: Mother- child relationship quality and emotion regulation. Journal of abnormal child psychology 37(6): 831-843.

13. Bekh B, Drew W, Kristina M, Elisabeth B, Tanja J, et al. (2011) Association between childhood maltreatment and adult emotional dysregulation in a low-income, urban, African American sample: Moderation by oxytocin receptor gene 23(2): 439-452.

14. Aldao A, Cicheti D, Kim J (2009) Mediating and modretats: mother-child relationship. Journal of ab chil 37(6): 831-843.

15. Abigail P, Amit E, Anett G, Bekh B, Tanja J, et al. (2015) Associations between childhood abuse, posttraumatic stress disorder, and implicit emotion regulation deficits: Evidence from a low-income inner city population 78(3): 251-264.

16. Crittenden PM, Di Lalla DL (1988) Compulsive compliance: The development of an inhibitory coping strategy in infancy. Journal of Abnormal Child Psychology 16(5): 585- 599.

17. Dorthie C, Negar F, Bekh B(2015) PTSD, emotion dysregulation, and dissociative symptoms in a highly traumatized sample. J Psychiatr Res 61: 174-179.

18. Lisa H, Maththias B, Claudi LH, David E (2016) Emotion regulation mediates the effect of childhood trauma on depression. Journal of affective disorders 198: 189-197.

19. Thomas C, Dorthie C, Abigail P, Bekh B (2014) Emotion dysregulation as a mediator between childhood emotional abuse and current depression in a low-income African- American sample. Child abuse negl 38(10): 1590-1598. 
20. Thomas E, Dorothea Q (2010) Emotion regulation difficulties in trauma survivors: The role of trauma type and PTSD symptom severity. Behavior Therapy 41(4): 587-598.

\section{ISSN: 2574-1241}

DOI: 10.26717/BJSTR.2018.06.001341

Eda Yllmazer. Biomed J Sci \& Tech Res

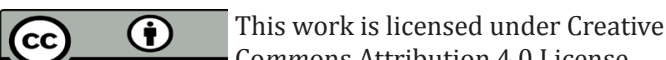

Submission Link: https://biomedres.us/submit-manuscript.php
21. WolffS, Holl J, Stopsack M, Hocker A, Staben KA, et al. (2016) Does emotion dysregulation mediate the relationship between early maltreatment and later substance dependence? Findings of the CANSAS study. European addiction research 22(6): 292-300.

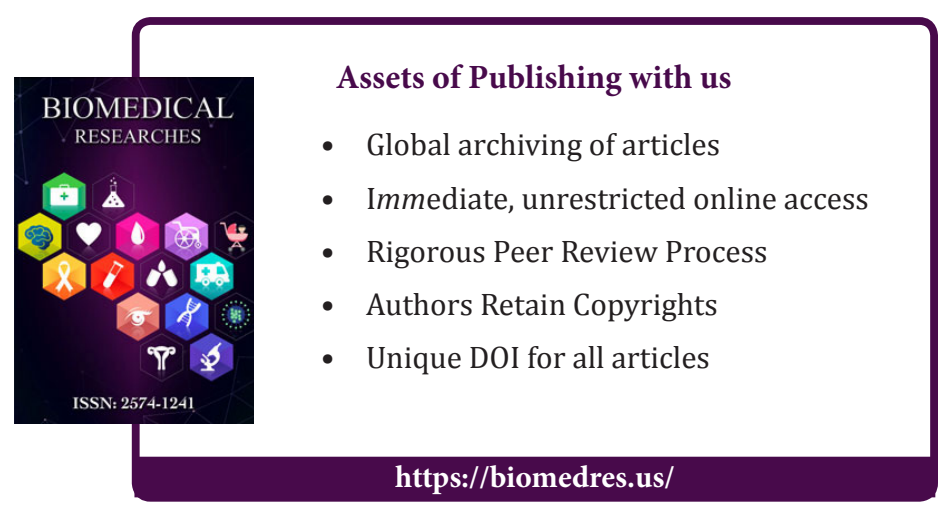

